\title{
Congenital Neuropathy
}

National Cancer Institute

\section{Source}

National Cancer Institute. Congenital Neuropathy. NCI Thesaurus. Code C27338.

Neuropathy, the cause of which is present at birth. 